\title{
Elektronik Atık (E-Atık) Geri Dönüşüm Merkezlerinin Maliyetlerinin Minimize Edilerek Kuruluş Yerlerinin Belirlenmesi
}

\author{
Melek Iş1k ${ }^{1 *}$, İran Macit ${ }^{2}$ \\ ${ }^{1}$ Çukurova Üniversitesi, Mühendislik Fakültesi, Endüstri Mühendisliği Bölümü, Adana, Türkiye (ORCID: 0000-0001-6078-7026) \\ ${ }^{2}$ Çukurova Üniversitesi, Mühendislik Fakültesi, Endüstri Mühendisliği Bölümü, Adana, Türkiye (ORCID: 0000-0001-5966-5726)
}

(İlk Geliş Tarihi 29 Ocak 2020 ve Kabul Tarihi 22 Şubat 2020)

(DOI: 10.31590/ejosat.680596)

ATIF/REFERENCE: Işık, M., \& Macit, İ. (2020). Elektronik Atık (E-atık) Geri Dönüşüm Merkezlerinin Maliyetlerinin Minimize Edilerek Kuruluş Yerlerinin Belirlenmesi. Avrupa Bilim ve Teknoloji Dergisi, (18), 224-231.

\begin{abstract}
$\ddot{O} \mathbf{z}$
Teknolojik gelişmeler ile kullanıcıların mevcut teknolojilerini yenileme istekleri hızla artarken eski elektronik eşyalara her gün bir yenisi eklenmektedir. Teknolojinin sunduğu son olanakları içinde barındıran ve piyasaya sunulan her yeni ürün, eski ürünleri rafa kaldırarak, bizleri de bilgi çağının ortaya çıkardığı elektronik atık (e-atık) gerçeğiyle yüzleştirmektedir. İlerleyen teknoloji ile ortaya çıkan yeni ürünler artarken tüketicinin kullandığı ürünler daha kullanım aşamasındayken elektronik atığa dönüşmektedir. Dünyada, en ciddi katı atık problemi yaşanan sektör elektrik ve elektronik endüstrisidir, çünkü bu endüstride demode olma ve hurda elektronik cihazlar artış göstermektedir. E-atıklar hem miktar açısından hem de içerdikleri etken maddeler açısından atıldıkları zaman insan ve çevreyi tehdit etmektedir. Günümüzde önemli olan elektronik atıkların doğaya zarar vermeden geri dönüşümlerinin sağlanarak yeni ürünler ortaya çıkarmada doğru yöntemlerle geri kazanmaktır. Yukarıdaki bilgiler doğrultusunda yapılan bu çalışmada, Türkiye'deki 38 şehirdeki elektronik atık toplama merkezlerinen gelen atıklar için seçilen 10 şehirden hangilerine geri dönüşüm merkezlerinin kurulmasına karar verecek matematiksel model kurulmuştur. Sonuçta seçilen bir şehire geri dönüşüm merkezi kurulması gerektiği tespit edilmiştir.
\end{abstract}

Anahtar Kelimeler: Elektronik Atık (E-atık), Geri Dönüşüm Merkezi, Matematiksel Model.

\section{Determination of the Establishment Places by Minimizing the Costs of Electronic Waste (E-Waste) Recycling Centers}

\begin{abstract}
With the technological advances, the desire of the users to renew their existing technologies is increasing rapidly and a new one is added to the old electronic devices every day. Each new product, which incorporates the latest opportunities offered by the technology and puts the old products on the shelf, confronts us with the fact of electronic waste (e-waste) created by the information age. While the new products emerging with the advancing technology increase, the products used by the consumers turn into electronic waste while they are in use. In the world, the solid waste problem is mostly faced by the electricity and electronics industry because products are getting obsolete and scraped in this industry. E-waste threatens the human and environment in terms of quantity and active substance they contain when they are disposed of. Nowadays, it is important to recycle electronic waste without damaging nature and to recover it with the right methods in creating new products. In this study which is performed according to the information above, a mathematical model is built that decides to in which of the selected 10 cities should be established recycling centers to meet the wastes collected from the waste collection centers among 38 cities of Turkey. As a result, it is determined that one recycling center should be established in one of the selected cities.
\end{abstract}

Keywords: Electronic Waste (E-waste), Recycling Center, Mathematical Model.

\footnotetext{
* Sorumlu Yazar: Çukurova Üniversitesi, Mühendislik Fakültesi, Endüstri Mühendisliği Bölümü, Adana, Türkiye, ORCID: 0000-0001-6078-7026, demirtasm@cu.edu.tr.
} 


\section{Giriş}

Günümüzde, elektronik aletler kullanılmadığı zaman ve kullanım süresini doldurdukları zaman bertaraf edilmeye hazır hale gelerek elektronik atık (e-atık) adını almaktadırlar. E-atıklar, elektronik aletlerin kullanıcısı tarafından ortaya çıkmaktadır. Gelişmiş ülkeler e-atıkların çoğunu meydana getirmektedirler ve e-atık problemini Asya ve Afrika ülkelerine ihraç ederek çözmeye çalışmaktadırlar. E-atıklar (Televizyon, bilgisayar, yazıcı, telefon, vb.) başlıca plastikler, metaller ve cam içermektedir. E-atıklar demonte edildiklerinde, geri dönüşüm için parçalandıklarında insan ve çevre sağlığını tehdit eden maddeler içermektedir.

Elektronik atık geri dönüşüm merkezlerinin yer tespiti bertaraf için önemlidir. Yer tespit ederken optimizasyon yönteminden yararlanılması ile optimum çözüm noktası tespit edilebilmektedir. Bloemhof-Ruwaard ve arkadaşları (1994), tesisler ile atık işleme üniteleri arasında eş zamanlı dağıtım ağı tasarımı ve bu ağda ürün akışı ve atık akışının koordinasyonu üzerine çalışmışlardır. Burada amaç, tesis ve atık işleme birimlerinin kurulum sabit maliyetlerini ve ürün ile atık akışı ile ilgili değişken maliyetlerinin toplamını minimize etmektir. Problem, tesislerdeki ve atık işleme birimlerindeki kapasite kısıtlarını, hizmet gerekliliklerini(üretim toplam talebi karşılamalıdır) ve üretim sonucu oluşan atıkların, atık işleme birimlerinde işlenilmesi kısıtlarını içermektedir. Kapasite kısıtları olan iki-seviyeli dağıtım ve atık işleme problemi için alternatif matematiksel modelleri ele almışlardır (Bloemhof-Ruwaard, Salomon, \& Van Wassenhove, 1994). Daniel ve arkadaşları (1997), yöneylem araştırması ile çevresel planlamaya katkıda bulunmayı amaçlamışlardır. Yöneylem Araştırmasının çevresel planlama ile dinamik ve etkileşimli olarak ilgili olduğu gösterilmiştir (Daniel, Diakoulaki, \& Pappis, 1997). Bircan ve Kartal (2003), kantitatif karar verme tekniklerinden doğrusal programlama tekniğinin işletme kapasitelerinin en kârlı biçimde kullanılması amacına yönelik bir çimento işletmesinde bir kapasite planlaması gerçekleştirmişlerdir. Çevre güvenliği açısından işletmenin son 4,5 yıllık verileri baz alınarak optimum kapasite kullanımı için bir pazar sınırlaması modeli geliştirilmiştir. Model ile fiili durumdaki işletmenin dar boğaz oluşturan üniteleri ve atıl kapasiteleri belirlenmiştir (Bircan \& Kartal, 2003). Kang ve Schoenung (2005), Amerika'da e-atık miktarı, mevcut geri dönüşüm programları ve geri kazanmak için mevcut çeşitli yöntemleri açıklamışlardır. Özellikle cam, plastik ve metaller için çeşitli geri dönüşüm teknolojileri incelemişlerdir (Kang \& Schoenung, 2005). Queiruga ve arkadaşları (2008), elektronik atıkların işlenmesi konusunda yapılan yeni Avrupa yasal düzenlemelerinin sonucunda, İspanya'da elektronik atık geri dönüşüm merkezleri kurulmasını araştırmışlardır. Geri dönüşüm tesislerinin kurulabilme uygunluklarına göre İspanya belediyelerini sıralayan bir metod sunulmuştur. Alternatifleri sıralamak için, çok kriterli karar metotlarından PROMETHEE (Preference Ranking Organisation Method for Enrichment Evaluations) uygulanmıştır (Queiruga, Walther, Gonzalez-Benito, \& Spengler, 2008). Nie ve arkadaşları (2009), belediye arıtma tesisinin genişletilmesi hususunda katı atık yönetim sistemi kurallarını içeren modelleme yaklaşımı uygulamışlardır (Nie, Huang, \& Li, 2009). Ahluwalia ve Nema (2011), elektronik atık yönetiminde maliyet, çevresel risk, sosyal olarak algılanan risk ve sağlık riskinin hedefleri için çok amaçlı bir karar destek modeli amaçlamışlardır (Ahluwalia \& Nema, 2011). Neto ve arkadaşları (2017), elektronik atıkların ekonomik ve çevresel avantajlarını ortaya koymak adına ikisi Brezilya'da biri İsviçre'de olmak üzere üç elektro-elektronik ürün üreticisi için geri dönüşüm ve yeniden kullanımını içeren tersine lojistik kavramını incelemişlerdir (de Oliveira Neto, Correia, \& Schroeder, 2017). Khoshand ve arkadaşları (2019), İran'da elektronik atıkların farklı alternatiflerinin değerlendirilmesi için bulanık AHP (Analitik Hiyerarşi Prosesi) yaklaşımına göre bir model geliştirmişlerdir. Veritabanı oluşturmak için bir anket yapılmış ve daha sonra her bir kriter açısından her alternatifin göreceli önemi değerlendirilmiştir (Khoshand, Rahimi, Ehteshami, \& Gharaei, 2019).

Geri dönüşüm tesisinin kuruluş yerinin belirlenmesi kararı, yapılan yatırımlardan ileriki dönemlerde en verimli şekilde yararlanmak amacıyla verilmesi gereken önemli bir karardır. Bu karar yanlış verildiği zaman işletmede birçok ciddi sıkıntılara yol açmaktadır. Buna bağlı olarak tesis yeri seçimi yüksek miktarda para ve zaman kaybına yol açmaktadır. Literatürdeki sezgisel ve matematiksel modeller uygulanabilirlik yönünden incelenmiştir. Literatürdeki uygulanabilir kısıtlarda göz önüne alınarak bir model sunulmuştur. Önerilen bu model, Türkiye'de elektronik atıkların toplanılması öngörülen 38 şehirden ve bu atıkların geri dönüşümünün yapılacağı 10 aday tesis yerinden seçilecek yer için matematiksel model oluşturulmuş ve yazılım aracılığı ile çözüm sunulmuştur.

\section{Materyal ve Metot}

Elektronik atıkların geri kazanılmasında Şekil 1.’ de görüldüğü üzere 2 ana teknik vardır. Birinci tekniğin ikinci tekniğe göre farklılığı kullanıcının girmesi ve el ile ayrıştırma yapılmasıdır. İkinci teknikte ise mekanik ayrıştırma yapılarak kırıcı makinede elektronik atıklar geri kazanılmaktadır. Bu tekniklerden biri seçilerek tesisin düzenlemesinin nasıl olması gerektiği tespit edilmektedir. 


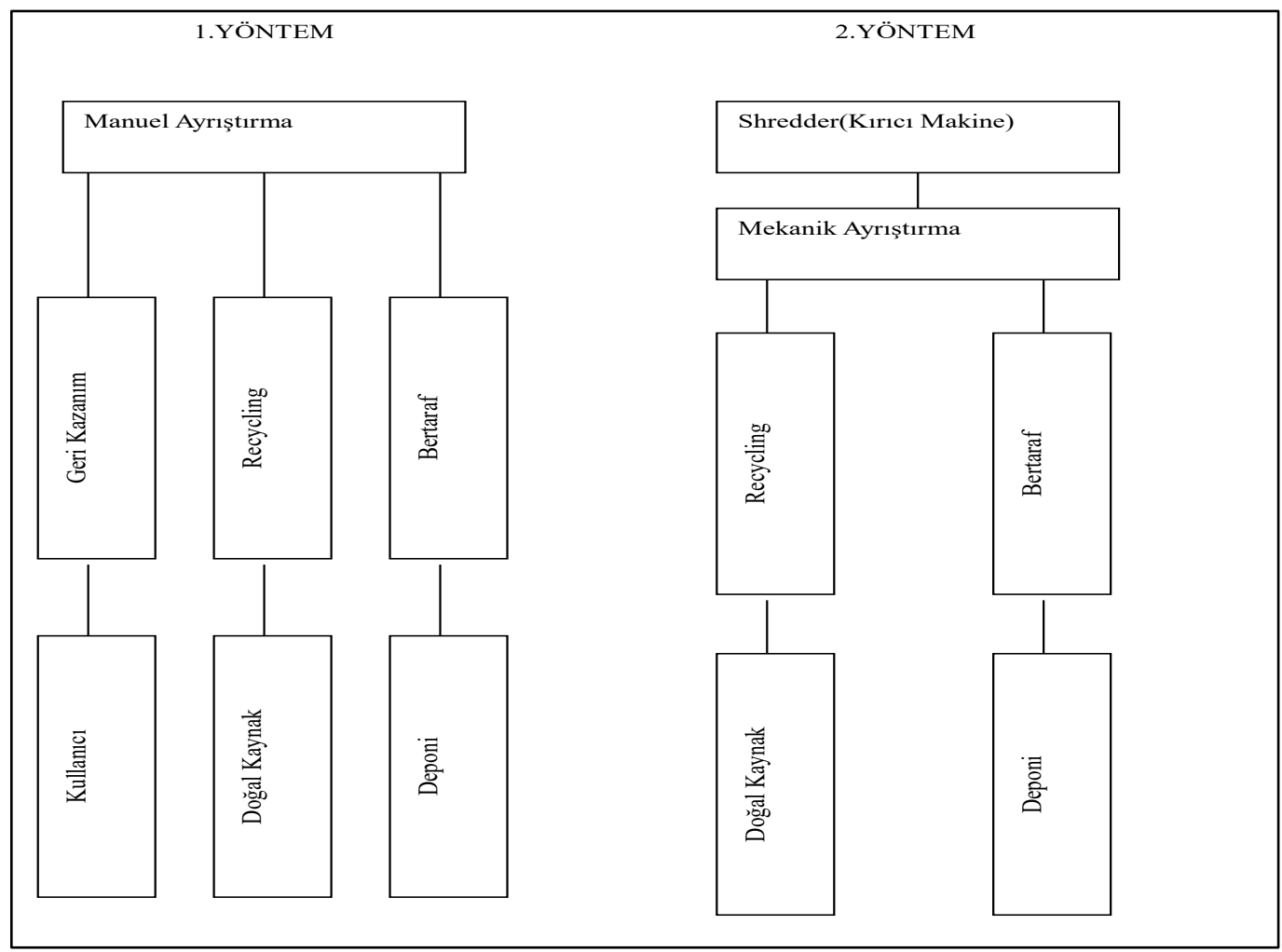

Şekil 1. Elektronik Atık Geri Kazanımı

\subsection{Yöntem}

1940’lardan bu yana yöneylem teknikleri geliștirilmiș ve bilgisayarların yardımıyla geleneksel kuruluş yeri seçiminde kullanılan çeşitli yöntemler oluşturulmuştur. Bu çalışmada, matematiksel model incelenmiş olup modeli çözmek için bilgisayar yazılımı kullanılmışır.

\subsubsection{Matematiksel Model}

Modelde eğer $\mathrm{n}$ adet aday yer içerisinden $\mathrm{m}$ adet tesis yeri belirlenecekse her tesis yalnızca bir aday yere atanabilir ve bir aday yere birden fazla tesis atanmaması koşulu vardır. Amaç fonksiyonu tüm maliyetlerinin toplamı en küçüklenmesi baz alınarak çözüme gidilmektedir (Daskin, 1995)

i: tesis sayısı için kullanılan indis $(\mathrm{i}=1,2, \ldots . \mathrm{m})$

$\mathrm{j}$ : aday yeri için kullanılan indis $\quad(\mathrm{j}=1,2, \ldots . . \mathrm{n})$

\section{Karar Değişkenleri:}

$y_{i j}=\left\{\begin{array}{l}1 \text { eğer i.tesis } \mathrm{j} . \text { aday yerine atanmış ise, } \\ 0 \text { aksi halde }\end{array}\right.$

\section{Parametreler:}

$c_{i j}=\mathrm{i}$ tesisini $\mathrm{j}$ aday yerine kurmaktan doğan maliyetlerin toplam $\iota$

\section{Amaç Fonksiyonu:}

$\operatorname{Minz}=\sum_{i=1}^{m} \sum_{j=1}^{n} c_{i j} y_{i j}$

\section{Kısitlar:}

$y_{i j}=\{0,1\}$ 
Modelde $y_{i j}$ i. tesisin j. yere atanıp atanmadığını gösteren karar değişkenidir. $c_{i j}$ kurulumdan doğan maliyetlerin gösterimidir. Denklem (1)' de amaç fonsiyonunda gösterilen toplam maliyetlerin minumum edilmesidir. Denlem (2)'de 0,1 tamsayı olma koşuludur.

\subsection{2. Önerilen Model}

Bu çalışma kapsamında, belirli şehirlerde var olan elektronik atık toplama merkezleri ile bu toplanan elektronik atıkların geri dönüşümlerinin yapılabileceği tesislerin en uygun yerleşim yerlerinin belirlenebilmesi için optimizasyon çalışması yapılmıştır. Modelde, matematiksel modelleme tekniğinden yararlanılmıştır. Varsayımlar aşağıda gösterilmiştir;

1) Türkiye'deki nüfusun 500.000'den fazla olduğu 38 şehirde elektronik atık toplama merkezleri kuruludur.

2) Geri dönüşüm merkezi kapasitesi 300000'dir.

3) Maksimum 10 tane geri dönüşüm merkezi kurulmaktadır.

4) Sadece açık olan tesislere taşıma yapılmaktadır.

Önerilen model, Türkiye içinde geri dönüşüm merkezlerinin minimum maliyet ile hangi illerde kurulacağını göstermektedir.

i: i. Şehirdeki Toplama Merkezi

$(\mathrm{i}=1,2, \ldots \mathrm{m})$

j: j. Geri Dönüşüm Merkezi

$(j=1,2, \ldots . n)$

\section{Karar Değişkenleri:}

$$
h_{j}= \begin{cases}1 & \text { eğer geri dönüşüm merkezi açık ise } \\ 0 & \text { aksi halde }\end{cases}
$$

\section{Parametreler:}

$s_{j}=\mathrm{j}$. geri dönüşüm merkezinin kurulum maliyeti

$w_{i}=\mathrm{i}$. toplama merkezinin e-atık miktarı

\section{Değişken:}

$c_{j}=\mathrm{j}$. geri dönüşüm merkezi kapasitesi

\section{Amaç Fonksiyonu:}

$\operatorname{Minz}=\sum_{j=1}^{n} s_{j} h_{j}$

\section{Kisitlar:}

$c_{j} h_{j} \leq \sum_{i=1}^{m} w_{i}$

$\sum_{j=1}^{n} c_{j} \leq C_{\max }$

$\sum_{j=1}^{n} h_{j} \leq P_{\max }$

$1 \leq \sum_{j=1}^{n} h_{j}$

$h_{j}=\{0,1\}$ 
Önerilen modelde, $h_{j}$ tesisin $\mathrm{j}$. yere atanıp atanmadığını gösteren karar değişkenidir. $s_{j}$ kurulumdan doğan maliyetlerin gösterimidir. $c_{j}$ geri dönüşüm merkezi kapasitesi ve $w_{i}$ toplama merkezlerinden gelen e-atık miktarıdır. Denklem (3) maliyeti minimize etmektedir. Kısıtlardan Denklem (4) kapasitenin talebi karşılama kısıtı, Denklem (5) geri dönüşüm merkezi kapasite kısıtı ve geri dönüşüm merkezi kapasitesi maksimum kapasitesi $C_{\max }=300000$ 'dir. Maksimum açılacak tesis sayıs $P_{\max }=10$ kısıtı da Denklem (6)'de verilmiştir. Denklem (7) ise en az bir tane geri dönüşüm merkezi kurulma kısıtıdır. Denlem (8)'de 0,1 tamsayı olma koşuludur.

\subsection{Materyal}

Türkiye'deki 38 şehrin elektronik atık toplama merkezleri için 10 şehirde geri dönüşüm merkezleri kurulması planlanmaktadır. $\mathrm{Bu}$ toplama merkezleri için yerleşim yerlerinin ve miktarının belirlenmiş kısıtlar ve varsayımlar doğrultusunda belirlenmesi amaçlanmıştır. Çalışmada aşă̆ıdaki verilerden yaralanılmıştır:

i. $\quad$ Şehirlerin yıllık elektronik atık üretme miktarları

ii. Elektronik atık geri dönüşüm merkezleri kurulum maliyetleri

Tablo 1. Illere göre fabrika kurulum maliyetleri(TL)

\begin{tabular}{lllll}
\hline & Bina Maliyeti & Makine Maliyeti & Arsa Maliyeti & Toplam Maliyet $\left(s_{j}\right)$ \\
\hline Adana & 1000000 & 400000 & 45000 & 1445000 \\
Ankara & 1000000 & 400000 & 337500 & 1737500 \\
Antalya & 1000000 & 400000 & 81000 & 1481000 \\
Bursa & 1000000 & 400000 & 270000 & 1670000 \\
Gaziantep & 1000000 & 400000 & 45000 & 1445000 \\
Mersin & 1000000 & 400000 & 45000 & 1445000 \\
İstanbul & 1000000 & 400000 & 1012500 & 2412500 \\
İzmir & 1000000 & 400000 & 337500 & 1737500 \\
Konya & 1000000 & 400000 & 9000 & 1409000 \\
Şanlıurfa & 1000000 & 400000 & 45000 & 1445000 \\
\hline
\end{tabular}

2010 yılında yapılan analize göre kurulması düşünülen 10 şehrin kurulum maliyetleri Tablo 1' de gösterilmişir. Tesis kurulum maliyeti bina kurulumu, makine maliyetleri ve arsa fiyatı baz alınarak hesaplanmıştır. Arsa maliyetleri 4500 metrekare arsa üzerinde kurulacaktır ve her bir şehirdeki organize sanayi bölgesindeki maliyetle çarpılarak bulunmuştur. TÜİK verilerine göre seçilen 38 şehirden çıkan elektronik atık miktarları Tablo 2' de gösterilmiştir. 
European Journal of Science and Technology

Tablo 2. Illere göre nüfus sayıları ve yılllk üretilen elektronik atı miktarları

\begin{tabular}{llll}
\hline İller & E-atık(ton) $w_{i}$ & İler & E-atık(ton) $w_{i}$ \\
\hline Adana & 30100 & Kayseri & 17476 \\
Adıyaman & 8741 & Kocaeli & 21569 \\
Afyonkarahisar & 10524 & Konya & 29386 \\
Ankara & 67001 & Kütahya & 8759 \\
Antalya & 26839 & Malatya & 10831 \\
Aydın & 14205 & Manisa & 19799 \\
Balıkesir & 16775 & Mardin & 11187 \\
Bursa & 36598 & Mersin & 23939 \\
Çorum & 8247 & Muğla & 11492 \\
Denizli & 13610 & Ordu & 10731 \\
Diyarbakır & 21911 & Sakarya & 12528 \\
Elazı̆̆ & 8119 & Samsun & 18434 \\
Erzurum & 11774 & Sivas & 9577 \\
Eskişehir & 10873 & Şanlıurfa & 22846 \\
Gaziantep & 23400 & Tekirdağ & 10926 \\
Hatay & 20793 & Tokat & 9311 \\
İstanbul & 188608 & Trabzon & 11109 \\
İzmir & 56090 & Van & 14695 \\
Kahramanmaraş & 15066 & Zonguldak & 9238 \\
\hline
\end{tabular}

\section{Araştırma Sonuçları ve Tartışma}

Bu çalışmada, Türkiye'nin nüfusu 500.000'den fazla olan 38 ili ele alınmış ve bu illerden toplanan elektronik atıkların işleneceği, toplama merkezlerinin kapasiteleri de göz önünde bulundurularak, en fazla 10 adet geri dönüşüm tesisi kurulması istenmektedir. Bu problemde geri dönüşüm tesisinin açıllp açılmama durumuna göre kurulum maliyetini minimize eden matematiksel model kurulmuş ve veriler GAMS programına girilerek optimum tesis yeri belirlenmiştir. Şekil 2.'de Türkiye'deki şehirler gösterilmiştir.

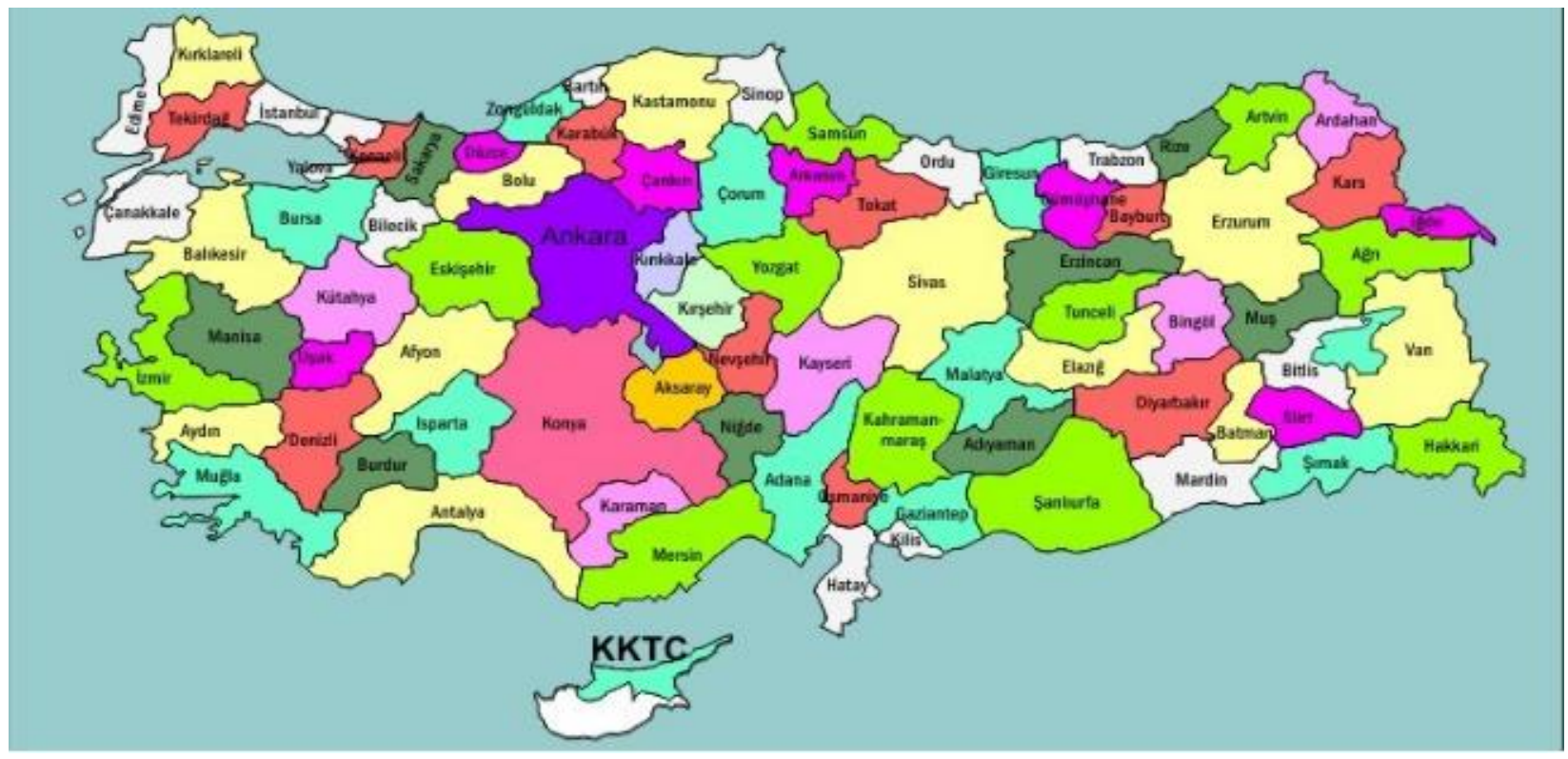

Şekil 2. Türkiye'de bulunan şehirler (web:t24.com.tr) 
Geri dönüşüm merkezlerinin kurulabileceği şehirler nüfus yoğunluğu bakımından şu şekildedir: Ankara, İstanbul, İzmir, Bursa, Adana, Konya, Antalya, Mersin, Gaziantep ve Şanlıurfa'dır. Geri dönüşüm merkezlerinin kapasite kısıdı göz önünde bulundurularak geri dönüşüm merkezi kurulum maliyetini minimize ederek gelen talep kısıdıyla optimum şekilde çözmek amaçlanmıştır. Elektronik atık geri dönüşüm merkezlerinin belirlenme kriterleri aşağıda gösterilmiştir.
a) Taşıma Maliyeti
b) Ulaşım Olanakları
c) Anayol Bağlantısı
d) Seçilen Tesislere Elektronik Atık Gönderen Şehirlerin Nüfus Yoğunluğu
e) Seçilen Tesislere Elektronik Atık Gönderen Şehirlerin Elektronik Atık Yoğunluğu
f) Seçilen Yerin Maliyeti
g) Arazi, İnşaat ve Kira Maliyeti
h) Arazinin Topografik Yapısı
i) Kredi Olanakları
j) İklim Föktörü
k) Teşvikler
1) Vergi ve Harçlar
m) Devletin Yatırım ve İskan Politikaları
n) Alt Yapı Hizmetlerine Erişim Kolaylığ1

Modelin sonucuna göre Şekil 3.’de işaretlenen 10 tane önerilen geri dönüşüm merkezlerinden 38 ilin e-atıklarının kazanımlarının yapılması için yuvarlak içine alınan Konya şehrine kurulması sonucuna ulaşılmıştır. Konum olarak merkezi bir yerde olması nedeniyle de tesis kurulması uygun görülmektedir.

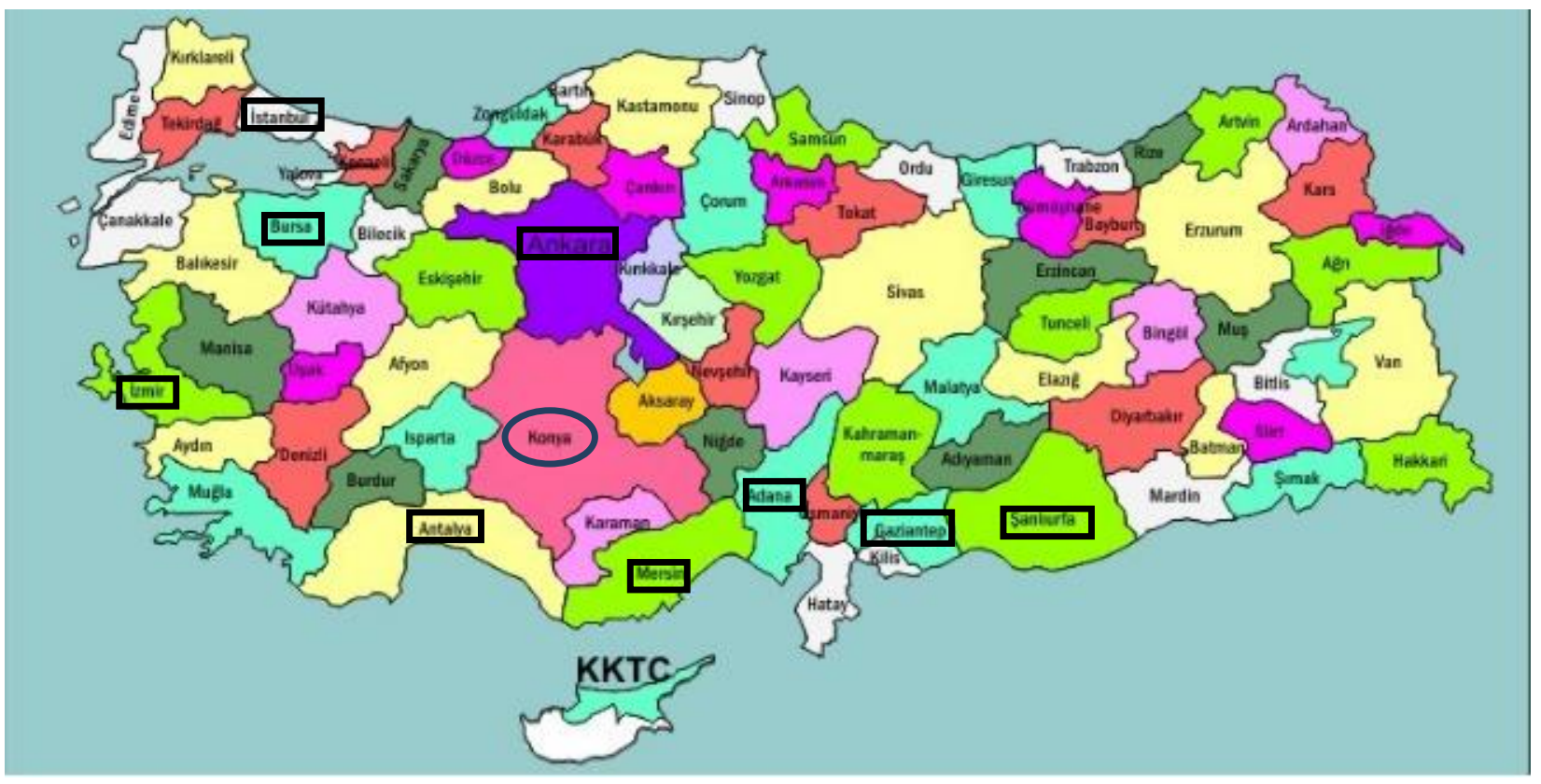

Şekil 3. Türkiye'de belirlenen geri dönüşüm merkezi şehirleri 


\section{Sonuç}

Hızla gelişen teknolojinin olumsuz tarafını oluşturan e-atıklar hızla dünyayı tehdit eder duruma gelmektedir. Çevre ve iş sahası oluşturma açısından düşünüldüğünde elektronik atıklar uygun yöntemlerle geri kazanılırsa önemli bir sektör olma yolundadır. Elektronik atıklar hem insan, çevre ve doğayı tehdit eden bir tehlike, hem de yeni iş imkanı sağlayacak ve yüksek getiri potansiyeli olan bir sektör olarak görülmektedir. E-atıklarla ilgili geri dönüşümün göz önüne alınması özendirilmektedir. Tehlikeli atıkların insan, çevre ve doğayı riske sokmadan bertarafı konusunda yeni teknolojiler geliştirilmektedir.

Elektronik atıklar göz önünde bulundurulduğunda çağımızın önemli sorunlarından birinin olması yanında yeni bir sektör oluşturması bakımından da büyük bir fırsattır. Yapılan çalışmada geri dönüşüm tesisinin kurulum, operasyonel, sabit maliyetlerini minimize ederek en fazla 10 şehirden hangilerine kurulması gerektiğine karar verilmesi amaçlanmıştır. Kısıtlarda toplam talebi karşılayacak kapasite bulundurulması koşulunu içermektedir. Önerilen modelde, Konya şehrine kurulması gerektiği sonucuna varılmıştır. Fakat bu çözümü iyileştirmek adına daha büyük veri setleri ile çalışıması ve yeni yöntemlerin denenmesi hedeflenmektedir. Gelecek çalışmalarda, geri dönüşüm merkezlerinin arttırılması ve bölgesel bazda değerlendirilmelerin yapılması amaçlanmaktadır.

\section{Kaynakça}

Ahluwalia, P. K., \& Nema, A. K. (2011). Capacity planning for electronic waste management facilities under uncertainty: multiobjective multi-time-step model development. Waste Management \& Research, 29(7), 694-709.

Bircan, H., \& Kartal, Z. (2003). Doğrusal programlama tekniği ile kapasite planlaması yaklaşımı ve çimento işletmesinde bir uygulamas1.

Bloemhof-Ruwaard, J. M., Salomon, M., \& Van Wassenhove, L. N. (1994). On the coordination of product and by-product flows in two-level distribution networks: Model formulations and solution procedures. European Journal of Operational Research, 79(2), 325-339.

Daniel, S. E., Diakoulaki, D. C., \& Pappis, C. P. (1997). Operations research and environmental planning. European journal of operational research, 102(2), 248-263.

Daskin, M.S., (1995). Network and Discrete Location: Models, Algorithms, and Applications. New Jersey, USA: John Wiley \& Sons, Inc., Hoboken, New Jersey.

De Oliveira Neto, G. C., Correia, A. d. J. C., \& Schroeder, A. M. (2017). Economic and environmental assessment of recycling and reuse of electronic waste: Multiple case studies in Brazil and Switzerland. Resources, Conservation and Recycling, 127, 4255.

Kang, H.-Y., \& Schoenung, J. M. (2005). Electronic waste recycling: A review of US infrastructure and technology options. Resources, Conservation and Recycling, 45(4), 368-400.

Khoshand, A., Rahimi, K., Ehteshami, M., \& Gharaei, S. (2019). Fuzzy AHP approach for prioritizing electronic waste management options: a case study of Tehran, Iran. Environmental Science and Pollution Research, 26(10), 9649-9660.

Nie, X., Huang, G. H., \& Li, Y. (2009). Capacity planning for waste management systems: an interval fuzzy robust dynamic programming approach. Journal of the Air \& Waste Management Association, 59(11), 1317-1330.

Queiruga, D., Walther, G., Gonzalez-Benito, J., \& Spengler, T. (2008). Evaluation of sites for the location of WEEE recycling plants in Spain. Waste management, 28(1), 181-190. 